\title{
WILLIAM SHAKESPARE EN AVIÑÓN. ANÁLISIS DE SU RECEPCIÓN EN EL CONTEXTO DE UN FESTIVAL DE TEATRO ${ }^{1}$
}

\author{
WILLIAM SHAKESPEARE IN AVIGNON. RECEPTION ANALYSIS \\ IN THE CONTEXT OF A THEATRE FESTIVAL
}

\author{
Isabel GUERRERO \\ UNED / Instituto del Teatro de Madrid (ITEM) \\ iguerrero@flog.uned.es
}

\begin{abstract}
Resumen: Este artículo analiza la representación de las obras de William Shakespeare en el Festival de Aviñón a través del análisis de los espectáculos y su recepción por parte del público y de la crítica con el objetivo de examinar cómo el contexto del festival da lugar a un tipo de recepción con características propias. Partimos de la idea de que la recepción del público en un festival de teatro es eminentemente distinta a la que tiene lugar en otros acontecimientos teatrales debido a las características particulares de este contexto. Para ello, exploramos tres aspectos fundamentales (la selección de montajes, la activación de la memoria del festival y la influencia del festival en los montajes que produce y coproduce), ayudados de la conceptualización semiótica del festival.
\end{abstract}

Palabras clave: Festivales de teatro. William Shakespeare. Festival de Aviñón. Recepción teatral. Puesta en escena.

\begin{abstract}
This article explores Shakespeare in performance at the Avignon Festival through theatre reviews and performance analysis in order to examine how festival contexts give rise to distinct types of audience reception. It takes as its starting point that audience reception at the festival context varies significantly from that in other theatrical events. The article interrogates three main aspects about the Avignon Festival (the influence of the curation of the festival, the activation of festival memories and the influence of the festival on commissioned productions) using semiotics to conceptualize the festival.
\end{abstract}

Keywords: Theatre festivals. William Shakespeare. Avignon Festival. Theatre reception. Mise-en-scène.

\footnotetext{
${ }^{1}$ La realización de este artículo ha sido posible gracias a la financiación de los proyectos de investigación "Shakespeare y el siglo XX: guerra, memoria cultural y nuevos media" (FFI2015-68871-P, Ministerio de Economía y Competitividad) y "Shakespeare y el siglo XX: afterlives mundiales y memoria cultural" (PGC2018-095632-B-I00, Ministerio de Ciencia, Innovación y Universidades), ambos dirigidos por Clara Calvo.
} 


\section{RICARDO II EN EL PALACIO DE LOS PAPAS}

La noche del 20 de julio de 2010, el público del Festival de Aviñón acudió expectante a la Cour d'honneur, el imponente patio interior del Palacio de los Papas, para ser testigo de un momento único en la historia del festival: la obra Ricardo II, de William Shakespeare, retornaba por primera vez en veintiocho años al palacio medieval del siglo XIV bajo la dirección de Jean-Baptiste Sastre. Desde el inicio de este afamado evento teatral en 1947, cuando fue representada por primera vez por Jean Vilar, esta obra ha estado estrechamente relacionada con la historia del Festival de Aviñón. El Ricardo II de Vilar, que utilizaba una traducción al francés encargada ex profeso a Jean-Luis Curtis para la ocasión, destacaba no solo por ser la obra inaugural del que se convertiría pronto en un célebre acontecimiento cultural en Europa, sino que, además, su escenificación incorporó varios elementos que hicieron de ella un hito en la historia de la representación de las obras de Shakespeare en Europa. Por ejemplo, una escenografía basada en un espacio vacío (algo que Peter Brook teorizaría años más tarde), la alteración del tradicional espacio a la italiana, sustituido aquí por un auditorio al aire libre similar al de los anfiteatros griegos y romanos, y un peso de la puesta en escena que recaía, casi al completo, en el trabajo actoral (March, 2012b; Falcon, 2007). El éxito del espectáculo fue tal que el montaje volvió a llevarse a escena en las ediciones de 1948, 1949 y 1953.

Treinta y cinco años después de la primera representación del Ricardo II de Jean Vilar, Arianne Mnouchkine, directora del Théâtre du Soleil, se atrevió a revisitar este título en el mismo espacio. La obra de Shakespeare sirvió de nuevo para indagar en la creación teatral, incorporando, esta vez, técnicas procedentes del teatro japonés como el Kabuki, el teatro Noh y el Kyogen. La combinación del texto de Shakespeare y el teatro oriental consiguió alejar el montaje de Mnouchkine del referente asentado por Vilar, contribuyendo con su propia visión de Ricardo II a la historia de las más relevantes puestas en escena del festival (Schwartz-Gastine, 2007). Debido a la importancia de los montajes de Vilar y Mnouchkine, Florence March (2010) ha señalado que la obra Ricardo II "finds itself at a mythological crossroads" en el Festival de Aviñón, lo que también explica la alta expectación ante el estreno de Sastre en 2010.

Aparte de enfrentarse a los dos míticos referentes, el montaje de Sastre atrajo todas las miradas por ser uno de los estrenos que se presentaban en esa edición y por tratarse de una coproducción del festival. Además, como March (2012b: 120-121) ha señalado, las expectativas del público se vieron incrementadas debido a los numerosos artículos y entrevistas que aparecieron en la prensa con anterioridad al estreno, donde se hacía referencia explícita a los montajes de Vilar y Mnouchkine, a la exposición que organizó el propio festival en torno al montaje de Vilar de 1947 y al espectáculo de danza Une semaine d'art en Avignon, donde se hacían numerosas menciones a la mítica propuesta de la primera edición. Todo esto contribuyó a la reactivación de la memoria del festival (March, 2012b: 120), debido a la cual el montaje de Sastre no podía ser percibido como 
una representación más de Ricardo II, sino que se erigía como un claro ejemplo de representación de este título en el Festival de Aviñón; el horizonte de expectativas que generaba estaba claramente determinado por el contexto del festival y los referentes previos de Ricardo II. A pesar de las altas expectativas del público, o precisamente por culpa de estas, el espectáculo fue tachado de fracaso rotundo por la mayoría de los espectadores y críticos.

El Ricardo II de Sastre ilustra dos puntos fundamentales sobre la recepción en los festivales de teatro. Por un lado, permite ver cómo un montaje teatral es percibido como parte de la programación de un festival - debido a su estatus como coproducción-, y, por otro, cómo el festival crea un marco de referencia para la recepción en el que se ponen en contacto distintos montajes de la misma obra. En el presente artículo, nos adentraremos en la representación de Shakespeare en el Festival de Aviñón para examinar cómo un festival de teatro genera modos de recepción que son inherentes a estos acontecimientos. Según Henri Schoenmakers (2007: 28), "A festival is an event consisting of single events, in other words: a meta-event". Esta característica de los festivales de teatro implica que el meta-acontecimiento (meta-event), con su historia, su ideología y su selección de espectáculos en cada edición, condiciona la recepción de los montajes individuales, haciendo que la recepción del público sea eminentemente distinta a la que tiene lugar en otros contextos teatrales.

En los últimos años, han proliferado los estudios sobre las características generales de los festivales de teatro (véase, por ejemplo, Hauptfleisch et al, 2007; Zaiontz, 2018). Desde que Dennis Kennedy (1993) acuñara el término foreign Shakespeare que, más tarde, ha derivado en el estudio de lo que hoy en día se denomina global Shakespeare (Massai, 2005; Huang, 2009) — parcela dentro de los estudios shakesperianos dedicada al análisis de las apropiaciones en otras lenguas y tradiciones teatrales-diversos autores han prestado atención a las obras de Shakespeare que llenan los escenarios de numerosos festivales de teatro internacionales (Guerrero, 2017a; Guerrero, 2017b; Guerrero 2020; Kennedy, 2009; McConachie, 2010) ${ }^{2}$. Las representaciones de 2012 en el Globe to Globe Festival, celebrado en el Shakespare's Globe en Londres, y el World Shakespeare Festival, cuyos montajes pudieron verse por todo Reino Unido, tuvieron también una gran repercusión crítica (Edmondson, Prescott y Sullivan, 2013; Bennett y Carson, 2013; Prescott y Sullivan, 2015). Estos festivales fueron el germen de varios acercamientos a la recepción de las obras de Shakespeare en el contexto de los festivales de teatro atendiendo, sobre todo, a las lecturas globales y locales de los montajes y a la identidad de los espectadores que acudían a las representaciones (Purcell, 2015; Elfman, 2015). Florence March ha estudiado de forma profusa la relación entre Shakespeare y el Festival de Aviñón, como demuestran sus numerosos trabajos (por ejemplo, 2012a; 2012b; 2014;

\footnotetext{
${ }^{2}$ Como apuntamos en Guerrero (2020: 60), las obras de Shakespeare más representadas en el contexto de los festivales de teatro suelen coincidir con los títulos más canónicos como, por ejemplo, Hamlet o Macbeth. En el caso del Festival de Aviñón, las obras representadas con más frecuencia, hasta 2016, han sido Hamlet, con trece puestas en escena, Ricardo III, con nueve, y Macbeth, representada siete veces.
} 
2016, 2018). Sus investigaciones oscilan entre el estudio general de la relación entre el festival y el dramaturgo inglés y el análisis de distintas puestas en escena. En sus trabajos encontramos referencias a la recepción de las obras, tema que ha estudiado con mayor detenimiento en el caso del grupo de críticos amateurs del Groupe Miroir (March, 2012a).

El presente artículo, por tanto, busca contribuir a la investigación sobre festivales de teatro, la recepción y representación de las obras de Shakespeare desde una perspectiva distinta, poniendo el foco en el meta-acontecimiento del Festival de Aviñón. Para esto, partiremos del análisis de espectáculos y del estudio de críticas tanto profesionales como amateurs de distintos montajes de Shakespeare, en especial de aquellas obras representadas entre 2007 y 2016. Cabe destacar que el Festival de Aviñón no está por entero dedicado a la representación de las obras de Shakespeare, como sí es el caso de numerosos festivales dedicados al dramaturgo inglés que encontramos diseminados por la geografía europea ${ }^{3}$. No obstante, el caso de las obras de Shakespeare en el Festival de Aviñón resulta paradigmático para el estudio de la recepción en estos contextos debido a sus características especiales. Gracias al capital simbólico y cultural del dramaturgo, sus obras son, por un lado, conocidas por la gran mayoría del público que acude a festivales como el de Aviñón y, por otro, estas aparecen de manera regular en la cartelera reinterpretadas por distintos directores, ya que Shakespeare continúa siendo un punto de referencia para muchos artistas contemporáneos. Partiendo de estas premisas, diseccionaremos tres aspectos fundamentales de la recepción de los montajes de Shakespeare en el Festival de Aviñón: la selección de espectáculos que integran la programación del festival; la activación de la memoria del festival (fruto, normalmente, de la representación de una obra en concreto en distintas ediciones) y, por último, la influencia del festival en los montajes que produce y coproduce y que son representados, más tarde, en otros contextos. Para realizar dicho análisis, nos valdremos de la conceptualización semiótica de la estructura del festival, como exponemos en la siguiente sección.

\section{PROGRAMAR A SHAKESPEARE}

Los festivales de teatro, como es el caso del Festival de Aviñón, son producto de la selección de espectáculos y demás actividades que realizan sus directores artísticos, lo que permite describir los festivales como el fruto de dicho proceso de selección. Los directores artísticos del festival se encargan de designar a las compañías, obras y artistas, además de otras actividades paralelas como encuentros con artistas o exposiciones, por lo que el resultado final de la programación estará inevitablemente condicionado por su visión de las artes escénicas. En la historia del Festival de Aviñón los distintos directores artísticos se han valido de criterios y visiones disímiles para configurar las ediciones a su

\footnotetext{
${ }^{3}$ La asociación European Shakespeare Festival Network da cuenta de la cantidad y variedad de festivales dedicados a la representación de las obras de William Shakespeare en Europa, como es el caso, por ejemplo, de los festivales de Gdansk (Polonia), Indija (Serbia) o Craiova (Rumanía).
} 
cargo; no obstante, todos han sido fieles a los principios fundacionales bajo los que Jean Vilar creó el festival: la concepción de Aviñón como un laboratorio abierto a la creación, además de como plataforma de exhibición donde poder ver espectáculos nacionales e internacionales fruto de la creación contemporánea.

Para comprender cómo la recepción del público del festival se encuentra determinada por el acto de selección que realiza el director artístico, resulta de utilidad describir los festivales de teatro como sistemas semióticos. Sylvia Ostrowetsky (citada en Carlson, 1989: 11) introdujo la idea de la semiótica urbana, en la que los morfemas son los elementos que componen los edificios; los signos son los edificios individuales y los urbemas $^{4}$ se refieren a la totalidad de unidades integradas en una ciudad. Si tomamos esta idea como modelo para nuestro análisis, los morfemas serían los elementos que componen los distintos espectáculos, los signos serían los propios montajes y los festivalemas designarían a la totalidad de espectáculos que forman parte del festival. De este modo, los festivalemas serían el producto de los actos de selección del director artístico y funcionarían como una estructura macro-sintáctica en la que los espectadores pueden seleccionar los signos que desean para configurar su propia interpretación del festival dando lugar a su festivalema personal, es decir, a su propia selección de espectáculos dentro de la oferta establecida por la organización. Tendríamos así una lectura que no es nunca arbitraria, sino que está condicionada por el acto de selección previo del director artístico, pero que, en última instancia, estará determinada por el acto de selección de los espectadores.

Los espectáculos que integran una determinada edición de un festival pueden ser seleccionados, simplemente, porque estén disponibles en ese momento y se encuentren dentro su línea artística o bien porque respondan a una temática concreta a la que se haya decidido dedicar esa edición. En los festivales, ya sean de teatro o de otras artes, es habitual que las distintas ediciones respondan a temáticas determinadas, lo que condiciona la elección de los espectáculos según este parámetro y que, además, tiene un efecto particular en la recepción de los espectadores. En este sentido, es frecuente, por ejemplo, dedicar el programa de cada edición, o al menos una parte de este, a un país o una parte concreta del planeta ${ }^{5}$. En el caso de Aviñón, el festival nunca ha estado determinado por restricciones temáticas estrictas. No obstante, Oliver Py, director desde 2014, y sus predecesores, Hortense Archambault y Vicent Baudriller, directores desde 2004 hasta 2013, han trabajado en sus programaciones con la noción de "idea subyacente", una idea general que gobierna la programación de cada edición y que el público puede descubrir a través de distintos espectáculos. Esta idea subyacente, que está normalmente relacionada con cuestiones de actualidad pertenecientes al mundo del arte o la política, aparece explicitada en el mensaje de apertura que el director artístico incluye

\footnotetext{
${ }^{4}$ Traducción que realizamos del término urbemes empleado por Ostrowetsky.

${ }^{5}$ El Festival de Teatro Clásico de Almagro inició esta línea de programación en su edición de 2019, designando a México como el país invitado, por lo que buena parte del programa estaba compuesto por artistas y compañías procedentes de dicho país.
} 
en el programa de cada edición. Dicha idea no tiene por qué aparecer en todos los espectáculos, pero sí que es común a muchos de ellos, lo que permite a los espectadores interpretar y conectar las distintas representaciones a las que asiste, creando así un festivalema propio en el que muchos de los signos (los espectáculos) presentan cierta conexión temática.

En 2008, por ejemplo, Archambault y Baudriller (2008: 2) apuntaban en su mensaje de apertura que la configuración de la edición se basaba, en parte, en el alto compromiso político: "Parce qu'elle embrasse le mystère de l'être humain dans toute sa complexité, parce qu'elle sollicite l'intelligence du spectateur et respecte sa liberté de regard face aux spectacles, cette édition est politique et résiste aux tentations de simplification qui nous entourent". Así, los dos montajes de Shakespeare de la edición podían interpretarse a partir de esta idea: Hamlet, coproducción del festival dirigida por Thomas Ostermeier con su compañía la Schaubühne, abordaba la problemática de la legitimidad del poder, y Tragédies romaines, espectáculo dirigido por Ivo van Hove que aunaba en un montaje de seis horas de duración la representación de Coriolano, Julio César y Antonio y Cleopatra, invitaba al público a reflexionar sobre la política del momento, estableciendo constantes paralelismos entre los aconteceres políticos de las tres obras y nuestro tiempo. Para potenciar esta reflexión, Tragédies romaines se valía de una estética contemporánea basada en un amplio despliegue tecnológico con cámaras y pantallas repartidas por todo el espacio escénico, lo que permitía realizar retrasmisiones en directo tanto dentro como fuera del teatro, además de mostrar grabaciones de boletines informativos de acontecimientos políticos pasados y de actualidad. Además de compartir la política como temática, Hamlet y Tragédies romaines ofrecían a los espectadores la libertad a la que hacían referencia Archambault y Baudriller en su mensaje, poniendo de relieve la relación entre escena y público. Por un lado, la representación de Hamlet incluía varios momentos en los que se rompía la cuarta pared al iluminar el patio de butacas y dirigirse los actores directamente a los espectadores. Por otro, Trágedies romaines optaba por disolver de forma casi total la cuarta pared, invitando al público a ocupar el mismo espacio que los intérpretes.

Las reacciones a un momento en particular de Hamlet ponen de manifiesto, de forma aún más explícita, las posibilidades de que el público del festival relacionara la producción con la idea subyacente de la edición. Tras el entierro del padre de Hamlet con el que comenzaba el espectáculo (momento que no aparece en escena en la obra de Shakespeare), la actriz que encarnaba a Gertrudis entonaba, micrófono en mano, la canción "L'amour", de Carla Bruni. Dado que la función se representaba en alemán con sobretítulos en francés, este era uno de los pocos momentos en los que el público, en su mayoría francófono, tenía acceso lingüístico directo a lo que se decía en escena. La letra de la canción afirma de forma reiterada "l'amour pas pour moi", lo que llevó a gran parte de los espectadores a interpretar la letra como un comentario sobre la estrategia de Gertrudis al casarse con el hermano de su difunto esposo, dejando entrever que su nuevo matrimonio con Claudio no era fruto del amor. Aparte de esta lectura, que desvela solo 
una de las posibles interpretaciones acerca de las razones que llevan a Gertrudis a casarse con Claudio que permite la obra de Shakespeare, la canción también dio pie a la asociación de Gertrudis y la cantante Carla Bruni, quien precisamente había causado sensación en las revistas del corazón ese mismo verano por su reciente matrimonio con el entonces presidente de Francia Nicolas Sarkozy ${ }^{6}$. La comparación entre Bruni y Gertrudis acarreaba con ella la consecuente equiparación de Claudio y Sarkozy, proveyendo así de un contexto de referencia familiar para la mayoría de los espectadores. Esta identificación de los personajes con Bruni y Sarkozy fue posible gracias a la representación del montaje en Aviñón en ese momento en particular, por lo que es posible que la canción se hubiese incluido de forma deliberada para alcanzar dicho efecto. Años más tarde, cuando el montaje seguía siendo representado en la sede de la compañía en Berlín, la canción había perdido ya las connotaciones que tuvo en el festival en 2008.

El que la idea subyacente del festival fuese la política condicionó en cierto sentido la recepción tanto de Hamlet como de Tragédies romaines, sobre todo de la primera, posiblemente por haber sido una coproducción del festival. Schoenmakers (2007: 36) ha sugerido que "The more the festival organisers have claimed a more specific aim in public statements, the more these statements will function as norms for the evaluation of performances". Como variación de esta hipótesis, añade "the more the spectators have been engaged in the information of the festival organisers, the more they will show agreement in their evaluation" (Schoenmakers, 2007: 36). El hecho de que la idea subyacente del festival no domine la narrativa general de las distintas ediciones - es decir, no se publicita de forma tan explícita a como se haría con una edición temática, ya que esta solo aparece en el mensaje de apertura del director artístico-, implica que esta idea no va a influir necesariamente en la recepción de todos los espectadores de forma directa, sino solo en la de aquellos que interactúen con la información proporcionada por la organización.

Los críticos profesionales que asisten al festival, así como los miembros del grupo de críticos aficionados Groupe Miroir, son un ejemplo de espectador activo que está en contacto directo con la información que provee la organización y cuya recepción, por tanto, estará determinada por el mensaje del director. En una de las reseñas realizadas para el Groupe Miroir, Alain Maldonado (2008), uno de los miembros fundadores de este colectivo, pone en relación el Hamlet de Ostermeier con la idea del festival, realizando un análisis que tiene en consideración la dimensión política como base que había articulado esa edición ${ }^{7}$. De manera similar, el periódico L'Humanité incluyó un resumen de la edición bajo el título "Une vision politique d'Avignon" (Han, 2008: s. p.),

\footnotetext{
${ }^{6}$ Varios críticos hacen referencia a esta asociación. Véase, por ejemplo, Bély, 2008: s. p.; Le Breton, 2008: s. p.

${ }^{7}$ En palabras de Maldonado (2008: 96) "la thématique principale du Festival et de sa dimension politique. Faut-il dans cette pièce: y voir la difficulté d'assumer une responsabilité politique sans avoir un détachement suffisant à l'égard de toute forme d'amour et, d'autre part, réaliser que le jeu politique, tel un duel même symbolique, conduit à la mort des protagonistes?"
} 
centrándose en el compromiso político de varios espectáculos. Aunque esta panorámica del festival no hacía mención a Tragédies romaines, sí que incluía Hamlet, espectáculo que mencionaba junto a otras propuestas como L'Enfer, de Romeo Castellucci, o La mélancolie des dragons, de Philippe Quesne, observándolas también desde una interpretación política.

Así como el público puede configurar libremente su propia lectura del festival, a través de la selección de los montajes a los que desean asistir, componiendo lo que hemos denominado como festivalemas personales, también pueden establecer conexiones entre las producciones que sean independientes de la idea subyacente planteada por los directores artísticos. En este sentido, por ejemplo, los miembros del Groupe Miroir no solo escriben reseñas de los montajes individuales a los que asisten, sino que también realizan una narración de su experiencia global durante el festival en la que establecen conexiones entre los distintos espectáculos. Estas reseñas sobre cada edición son denominadas como tráversées, término que podríamos traducir como "itinerarios". En estos itinerarios encontramos frecuentes menciones a representaciones de William Shakespeare junto a obras de otros autores, cosa que pone de manifiesto la dimensión global que alcanza la recepción de los espectáculos en el marco del festival, haciendo que los distintos montajes no solo puedan interpretarse en su individualidad, sino que se presentan, de forma explícita, como parte del conjunto de la programación.

En su itinerario de la edición de 2015, Maldonado comparaba su experiencia personal en el festival con una ópera, divida en actos y escenas, en un intento creativo por encontrar "la fable (ou la proposition) mise en scène par le Directeur du Festival Olivier Py et son équipe" (Maldonado, 2015: 330; mi énfasis). Su narración del festival como una ópera, utilizando la metáfora de la escenificación para explicar el acto de programar realizado por el director artístico, comienza con Rey Lear, dirigida por el propio Oliver Py, la producción que abría el festival en la Cour d'honneur. Maldonado hace hincapié en la importancia que adquiere el poder del lenguaje en el montaje, algo más subrayado si cabe en el silencio de Cordelia. En el mismo acto de esta ópera construida por Maldonado, se incluye también Antonio y Cleopatra, dirigida por el portugués Tiago Rodrigues, otra pieza centrada en la comunicación, esta vez entre hombres y mujeres en cargos de poder. Maldonado (2015: 332) incluye el tercer montaje de una obra de Shakespeare en un acto aparte, que titula como "Act 3. La fascinante tension de vouloir 'être ou ne pas être' et la montée du fascisme". El análisis de esta pieza ahonda en el poder manipulativo del lenguaje que realiza el personaje de Ricardo III.

Si para Maldonado el mensaje o la idea subyacente de la edición se centra claramente en la comunicación, por su parte, Oliver Py había establecido la otredad, la figura del otro como idea principal (Py, 2015: 1). En el mensaje introductorio, Py hace hincapié en cómo la cultura y la educación son esenciales para superar el miedo a lo desconocido, el miedo al otro, que reinaba en Francia tras los atentados a la revista Charlie Hebdo que habían tenido lugar meses antes. No obstante, la lectura que Maldonado realiza de su paso por el festival no está relacionada directamente con la propuesta del director, por lo que su 
narración muestra cómo la experiencia individual de cada espectador puede generar sus propios significados en la recepción de las obras. El ejemplo de Maldonado pone de manifiesto cómo los espectadores, gracias a su selección individual de espectáculos dentro del festivalema general, pueden construir su festivalema personal, cuyo significado puede diferir del establecido por la organización.

\section{WILLIAM SHAKESPEARE Y LA MEMORIA DEL FESTIVAL}

El análisis anterior está condicionado por el hecho de que la representación de las obras de Shakespeare en el contexto de un festival de teatro no tiene lugar de forma aislada, sino que se percibe como parte del conjunto de actividades y espectáculos. Esto implica que la recepción en este contexto esté altamente influenciada por la recepción del resto del programa. Una de las primeras y más evidentes conexiones entre espectáculos de la misma edición es la que se establece entre montajes de distintas obras de Shakespeare que comparten programa. Como signos pertenecientes al conjunto del festival, estos espectáculos, por lo general, son percibidos como miembros de la misma categoría precisamente porque tienen su origen en el dramaturgo inglés, lo que permite establecer una comparación más directa e inmediata entre ellos. La categorización de los montajes como "shakesperianos" se relaciona con la idea de autoridad expresada por William B. Worthen $(2003,3)$ :

For despite "the death of the author" (Barthes), or the author's functional absorption into the systems of cultural and ideological production (Foucault), "Shakespeare" — sometimes coded as the "text," its "genre," or the "theatre" itself- remains an apparently indispensable category for preparing, interpreting and evaluating theatrical performance, at least as much for practitioners as for scholars and critics.

Dejando a un lado la utilidad que el término "shakesperiano" pueda tener para creadores artísticos y académicos, esta categoría es fundamental en la recepción y evaluación de un montaje por parte del público, puesto que los espectáculos que reconocen o revelan alguna conexión con Shakespeare son proclives a ser percibidos como miembros de la misma categoría con independencia de su género o estilo. La traversée de Maldonado en la edición de 2015 que veíamos en la sección anterior es un ejemplo de esto, con la agrupación de Rey Lear y Antonio y Cleopatra en una misma sección. Armelle Héliot (2015), periodista de Le Figaro, realizó algo similar comparando en una de sus críticas dos de los montajes de Shakespeare de la misma edición, en este caso el Rey Lear de Py y Ricardo III de Ostermeier, comparativa en la que esta última salió claramente beneficiada puesto que, para Héliot, "Richard III fait oublier la dérouillée d'Oliver Py". El que Héliot elija Rey Lear para relacionarla con Ricardo III en vez de escoger otro espectáculo fallido del festival no es casualidad; selecciona la contraparte lógica; es decir, otro montaje también del dramaturgo inglés. 
Los festivales regulares como el de Aviñón generan un marco de referencia que permite a sus espectadores habituales establecer no solo conexiones entre los montajes de una misma temporada, sino también con los de ediciones pasadas. Este marco de referencia permite articular el concepto de "memoria del festival", esto es, el conjunto de memorias de los espectadores sobre sus experiencias en este contexto. En este caso, los significados de los festivalemas, tanto globales como individuales, de distintas ediciones se superponen, dando lugar a conexiones que son de especial relevancia en el caso de los montajes de Shakespeare, ya que los enlaces entre estos se crean de forma sencilla por ser percibidos como miembros de la misma categoría, como hemos visto anteriormente. Esto permite al público del festival crear un tipo específico de memorias relacionadas con las obras de William Shakespeare, que son proclives a ser activadas aún más cuando se trata de montajes de la misma obra debido a su origen en una fuente común.

En las primeras décadas del siglo XXI, los espectadores habituales del Festival de Aviñón han tenido la oportunidad de activar su memoria de Shakespeare en Aviñón gracias a tres visiones diferentes de Ricardo III: las dirigidas por Ludovic Lagarde (2007), Angelica Liddell (2010) y Thomas Ostermeier (2015). Cada producción establecía una relación distinta con la obra de Shakespeare. Lagarde llevaba a la escena una versión escrita por el dramaturgo Peter Verhelst donde se hacía especial énfasis en el papel de los personajes femeninos. El espectáculo de Liddell estaba inspirado en el personaje de Ricardo, dando lugar a un texto en el que se entremezclaban las palabras y discursos de este con las propias reflexiones de la artista. Por su parte, Ostermeier empleaba una traducción al alemán en prosa realizada para la ocasión por Marius von Mayenburg, quien también introdujo pequeñas adaptaciones de la obra con vistas a su puesta en escena.

Como vemos, los tres montajes dan cuenta de disímiles estrategias textuales. Mientras que los trabajos de Lagarde y Ostermeier preservaban el título de Ricardo III, Liddell denominaba su pieza como El año de Ricardo. Los propios títulos son un claro indicativo de la negociación que se realizaba con la obra fuente: tanto Ostermeier como Lagarde permanecían próximos a Shakespeare, traduciendo parte de su contenido al alemán y francés respectivamente y siguiendo el argumento general, mientras que Liddell se valía solo del personaje de Ricardo. Los tres montajes localizaban la acción en el presente, dando pie a una crítica a la sociedad actual. En el Ricardo III de Lagarde, la vestimenta de Ricardo al ser coronado recordaba a la de numerosos dictadores del siglo XX, con gorra y uniforme militares; además, sus palabras contenían constantes referencias a discursos políticos contemporáneos como, por ejemplo, el afamado discurso de Martin Luther King que comienza con las palabras "I have a dream". Puestas en boca de Ricardo, estas palabras, llenas de luz y esperanza, se utilizaban para disfrazar sus malévolas intenciones. En el caso del montaje de Ostermeier, las acciones de Ricardo para enmendar su deformidad física (comienza la obra utilizando brackets en los dientes y se pone un corsé para disimular su joroba una vez que se convierte en rey) pueden interpretarse como una referencia a la ansiedad actual por adaptar nuestros cuerpos a los cánones de belleza, lo que enfatiza la relación entre la apariencia física y el poder. Remedios Perni (2015) ha 
analizado la producción de Liddell como un caso representativo de cómo la obra de Shakespeare sirve para reflexionar sobre la política actual, sobre todo en relación con el contexto de la crisis económica iniciada en 2008 en Europa. Perni (2015: 136) sitúa la producción de Liddell en el centro de una tendencia a acercarse al personaje de Ricardo en el siglo XXI que ella describe como "a rupture with any pastness, pushing Richard III out of time and place to, ironically, criticise the present" (cursiva en el original), análisis que puede hacerse extensible a los montajes de Lagarde y Ostermeier. Pese a este tratamiento dispar de la obra fuente, los tres montajes reforzaban la idea de autoridad shakespeariana de Worthen, siendo inmediatamente identificados por el público como ejemplos de la manifestación del teatro de Shakespeare en el siglo XXI.

De este modo, la recepción de los espectadores que asistieron a la representación de los tres espectáculos se habría visto afectada no solo por su memoria del festival, sino también por su conocimiento general de la obra de Shakespeare en cuestión. Como ha señalado Susan Bennett (1990: 151), "Where the text of performance is known to some or all the spectators, the mise-en-scène will likely be read against that knowledge". La familiaridad con el texto genera ciertas expectativas que el público trae consigo a la representación y que condiciona la recepción. Así, la memoria de otros montajes de Ricardo III tanto dentro como fuera del festival intervienen en este proceso de ghosting, término acuñado por Marvin Carlson (2001) para denominar la influencia que ejerce la memoria sobre la recepción teatral, cuyo papel, según él, se torna fundamental para nuestra comprensión de esta expresión artística. Debido a su fuente común (Ricardo III, de William Shakespeare) y a compartir el contexto de representación del Festival de Aviñón, las comparaciones entre producciones de la misma obra, incluso en distintas ediciones, son altamente posibles. La memoria de William Shakespeare en el festival, por tanto, puede ser considerada como una materialización del proceso de ghosting que indica Carlson, un proceso que se activa a través de la representación de obras shakesperianas en el contexto de un festival de teatro en concreto.

Lo que hemos denominado como la memoria de William Shakespeare en el festival suele ser el producto de la experiencia personal de los espectadores, pero también puede verse influenciada por la historia del propio encuentro y su narrativa oficial. El caso del Ricardo II de Sastre que comentábamos en la introducción a este artículo muestra cómo el festival invitaba a su público a recordar, o más exactamente reimaginar ${ }^{8}$, la producción fundacional de Vilar, lo que tuvo un efecto directo en las expectativas sobre el montaje de 2010. En este caso, la memoria del festival fue reactivada deliberadamente por la organización, con la decisión de programar Ricardo II junto a la exposición del montaje de Vilar y el espectáculo de danza en el que se evocaba la edición de 1947.

Numerosas críticas de espectáculos a lo largo del Festival de Aviñón dan cuenta de la presencia de la rememoración de Shakespeare, estando la recepción de los espectadores

\footnotetext{
${ }^{8}$ Realizar una invitación a la rememoración, en el sentido literal de la palabra, habría requerido que las producciones de 1947 y 2010 hubieran compartido un mayor número de espectadores de lo que permitía su separación temporal.
} 
condicionada por ella. Con frecuencia, los críticos profesionales se han valido de montajes previos de las obras de Shakespeare en Aviñón para contextualizar sus trabajos. En la crítica de Rey Lear, dirigida por Jean François Sivadier en 2007, para Le Monde, Fabienne Darge (2007: s. p.) escribía: "Bonheur de retrouver Shakespeare dans la Cour d'honneur, qu'il avait désertée depuis huit ans, depuis le Henry $V$ orchestré par JeanLouis Benoît en 1999”. El mismo sentido de satisfacción por el reencuentro de Shakespeare y el escenario en el Palacio de los Papas se percibe en la reseña del mismo espectáculo que realizó Vicent Mouret (2007: 149) para el Groupe Miroir: "Ce soir là, cette nuit là, Shakespeare a réintégré la Cour, toute la Cour; le plaisir et la force du théâtre est intact". Estas afirmaciones indican, por un lado, que los montajes de Shakespeare previos funcionan como punto de referencia para otros espectáculos a partir de sus obras $\mathrm{y}$, por otro, ponen de manifiesto la conexión histórica entre el Palacio de los Papas y este dramaturgo en el Festival de Aviñón.

La memoria del festival también se pone de manifiesto en las conexiones que se establecen entre los montajes de Shakespeare y de otros autores, conexiones que son proclives a aparecer, sobre todo, dentro de una misma edición. Estas comparativas suelen surgir por similitudes estéticas, culturales o lingüísticas. En 2001, una crítica comparaba Hamlet, dirigida por Krzystof Warlikowski, con Boris Gudonov, de Declan Donnellan, debido a la procedencia de ambas de Europa del este (Hamlet era una producción polaca, y Boris Gudonov fue representada por la sección rusa de la compañía Cheek by Jowl), su utilización similar de la relación entre el público y el escenario (en ambas el escenario se situaba en el centro del espacio, con el público alrededor) y la centralidad del trabajo actoral (Solis, 2001: s. p.). En la misma edición, el periódico canadiense Le Devoir publicaba una crítica conjunta de Macbeth y de un montaje de Ubú rey, aparentemente sin dar cuenta de la conexión existente entre ambos textos (Rioux, 2001: s. p.) ${ }^{9}$. Tras repasar el montaje de Ubú, el crítico en cuestión comentaba la representación de Macbeth preguntándose si "Le père et la mère Ubu ne sont-ils pas la caricature poussée à l'extrême, les sentiments en moins, de Macbeth et lady Macbeth?" (Rioux, 2001: s. p.). En contraste con estas dos comparativas, el resto de críticas disponibles en la Maison Jean Vilar, biblioteca que contiene los archivos del Festival de Aviñón, no dan muestra de ninguna otra conexión entre los montajes de obras de Shakespeare de esa temporada.

La comparación de Hamlet y Boris Gudonov muestra que, una vez que se representan las obras en el contexto de un festival, los montajes de Shakespeare dan pie a ser analizados como ejemplos de una tradición teatral específica, y no solo como representantes de la categoría de shakesperiano a la que nos referíamos con anterioridad. Por otra parte, la crítica de Ubú y Macbeth reactiva, aunque sea de forma inconsciente, la comparación entre montajes de la misma obra, sin importar que el proceso de adaptación se haya alejado bastante de la obra fuente, como en el caso de Ubú rey de Alfred Jarry. A la vista de todo lo expuesto, podemos concluir que los conceptos de memoria del festival

\footnotetext{
${ }^{9}$ Ubú rey es considerado por la crítica como una versión a partir del Macbeth de William Shakespeare. Véase, por ejemplo, Morse (2008).
} 
y memoria de Shakespeare en el festival proveen de dos marcos útiles para entender y conceptualizar el complejo proceso de recepción que tiene lugar en el marco de los festivales de teatro y su formación de festivalemas.

\section{PRODUCCIONES Y COPRODUCCIONES}

En ocasiones, la influencia del festival se manifiesta en la recepción de ciertos montajes que se representan en otros contextos, como sucede en el caso de los espectáculos producidos o coproducidos por el festival que inician más tarde su gira. Estos montajes suelen ser estrenados en el propio festival y, por tanto, tienen este como referencia en el proceso de ensayos. Como consecuencia, son más proclives a integrar elementos específicos del festival en la representación (como los espacios teatrales, el público, etc.) que otros montajes que, simplemente, incluyen el festival como una plaza más en su gira. Si bien los montajes en gira han de adaptar su representación a las condiciones del festival, las producciones y coproducciones se desarrollan con comodidad en Aviñón, activando más tarde la posibilidad de su realización en otros contextos. El Ricardo II de Jean Vilar puede ser considerado la primera producción propia del festival, no ya en el sentido que entendemos hoy en día de un encargo para ser estrenado en un festival de renombre, sino en el de haber sido creado específicamente para su representación en Aviñón. Aunque varias críticas del momento señalan que las primeras representaciones denotaban cierta falta de control técnico sobre el espacio, ya que la propuesta al aire libre hacía que no se oyera del todo bien a los actores ${ }^{10}$, el montaje había sido diseñado para dicha ocasión. Cuando la puesta en escena de Vilar fue representada en su gira en el Théâtre des Champs Elysées en París en el otoño de 1947, fue necesario adaptar la obra para ser representada en un teatro a la italiana, abandonando así las condiciones especiales de escenificación al aire libre del Palacio de los Papas. En una carta al editor de la sección de teatro del New York Times, un espectador que había acudido a la representación de la obra tanto en París como en Aviñón llamaba la atención sobre cómo, según él, el montaje había perdido parte de su atractivo en el proceso de adaptación al nuevo espacio en el teatro parisino: "This play, which had been directed for another cadre, another scale, had been brought indoors; and indoors its notes rang false. Grandeur became bombast and even the simplicity of the conception seemed to be just another theatrical trick"11 (Savacool, 1948: s. p.; mi énfasis, en francés en el original). El espectador continúa afirmando que "Re-set in its original cadre at Avignon, it regained its original effect" (mi énfasis, en francés en el original). Este testimonio, en el que el éxito o fracaso de la representación se vincula estrechamente al espacio para el que había sido diseñada, describe el montaje casi como site-specific, ya que es solo en la Cour

\footnotetext{
${ }^{10}$ Varias críticas señalan que este fue uno de los problemas de la representación en la Cour d'honneur. Véase, por ejemplo, Dornes, 1947: s. p.; Anónimo, 1947: s. p.

${ }^{11}$ En esta carta, John Savacool comparaba la representación en París en 1947 con la del Festival de Aviñón de 1948.
} 
d'honneur donde Ricardo II recobra su esplendor. La representación de Ricardo II en otros espacios escénicos fuera de Aviñón parece haber sido más exitosa, como en el caso del Festival Internacional de Edimburgo en 1953, donde la prensa acogió el trabajo de Vilar con grandes elogios ${ }^{12}$.

Más recientemente, Au moins j'aurai laissé un beau cadavre, una adaptación de Hamlet coproducida por el festival en 2011 dirigida por Vicent Macaigne, sirve también de ejemplo para ilustrar cómo el festival se erige como punto de referencia para montajes de Shakespeare que son representados posteriormente en otros contextos. La propuesta tomaba la obra de Shakespeare y una de sus fuentes principales (el texto escandinavo del siglo XII, La vida de Amleth, de Saxo Grammaticus) como punto de partida. En términos generales, la acción seguía el argumento de la obra del dramaturgo inglés, pero prestaba más atención a Claudio - transformado aquí en líder carismático-, que a la trama de venganza del príncipe Hamlet. El montaje tuvo el privilegio de poder realizar sus ensayos generales en el Cloître des Carmes, el claustro medieval donde se estrenaría en el marco del Festival de Aviñón. La interacción con los espectadores fue uno de los puntos más destacados de esta versión de Hamlet, ya que el montaje ponía de relieve el papel activo del público. Conforme los espectadores entraban en el recinto teatral, se les invitaba a subir al escenario y bailar y cantar con los actores, a modo de celebración. Este inicio servía para marcar el tono alegre y paródico del espectáculo, que se confirmaba una vez que la representación propiamente dicha comenzaba y aparecían elementos tan extravagantes como Claudio vestido con un disfraz de plátano o la encarnación del fantasma del fallecido rey Hamlet en un hurón disecado.

El montaje estaba tan estrechamente ligado a su representación en Aviñón que dio lugar a interpretaciones solo posibles en dicho contexto. El caos reinaba en su última escena: un castillo inflable deshinchándose, sangre, césped, serpentinas e, incluso, una cabra que paseaba por allí inundaban el escenario mientras los personajes, uno por uno, se sumergían en un acuario, emulando así el ahogamiento de Ofelia. Estas imágenes de puro desorden llevaron a un crítico a comparar el caos reinante en Aviñón durante el festival con la imagen plasmada en la escena: "En sortant du spectacle, traversant Avignon la nuit, nous nous souvenons du chaos sur la scène du cloître des Carmes en regardant les rues pleines de détritus, d'affiches déchirées dans le caniveau et d'odeur de pisse et de bières mêlées" (Menard, 2011: s. p.). Cuando el montaje fue representado en el Teatro Nacional de Chaillot en París unos meses más tarde, las mismas imágenes caóticas debían adaptarse al nuevo contexto. Allí, el crítico de L'Expreess (Libiot, 2011: s. p.) presentaba el montaje haciendo referencia al Festival de Aviñón ("Le souvenir d'Avignon est encore intense"), y evocando la representación bajo el cielo estrellado del festival. A pesar del tono melancólico de la remembranza del festival, el montaje

12 El crítico del Evening Dispatch dijo sobre esta puesta en escena en el Festival Internacional de Edimburgo: "There is a miracle of Shakespeare to be seen at the Royal Lyceum Theatre, a truly international Festival offering" (H., 1953: s. p.). El titular de la reseña publicada en el Scotsman ("M. Vilar's Richard II. Striking Production by French Company") también da cuenta del éxito de la representación en Edimburgo (Anónimo, 1953: s. p.). 
consiguió desterrar las referencias a Aviñón, sustituyéndolas, finalmente, por las de la ciudad de la luz, lo que evidencia la adaptación satisfactoria al nuevo contexto ${ }^{13}$. Retomando la perspectiva semiótica, podemos ver cómo, insertado en distintos contextos, la lectura del mismo signo (el espectáculo Au moins j'aurai laissé un beau cadavre) da lugar a significados distintos, aunque, en un primer acercamiento, sigue evocando la atmósfera del festival en el que fue creado.

\section{CONCLUSIONES}

Desde el Ricardo II de Jean Vilar en 1947 a los montajes de Shakespeare más recientes como los dirigidos por Ostermeier (Hamlet, 2008; Ricardo III, 2015), Sastre (Ricardo II, 2010) o Macaigne (Au moins j'aurai laissé un beau cadavre, 2011), la recepción y representación de las obras de Shakespeare en el Festival de Aviñón se ha visto marcada por las características propias de este contexto, debido a la activación de unos determinados mecanismos de recepción generados por la estructura del festival. La representación de las obras de Shakespeare en Aviñón ha dado lugar a montajes cuya interpretación ha estado ligada a dicho contexto o, al menos, ciertos elementos han sido percibidos de manera determinada debido a su representación en el festival. En ocasiones, las ideas subyacentes introducidas por los directores artísticos han sido la causa de tales interpretaciones. Estas ideas han afectado a la recepción tanto de los montajes de manera individual (los signos independientes) como del conjunto de espectáculos (el festivalema general determinado por la selección del director artístico o el festivalema personal de cada espectador). Debido a sus características, las producciones y coproducciones del festival se asocian frecuentemente con este, incluso estando de gira en otros contextos, lo que demuestra la importancia del festivalema para la interpretación del signo. Como demuestra el análisis de la representación de las obras de Shakespeare en el Festival de Aviñón, en este festival o, en general, en cualquiera de características similares, la recepción de las obras de Shakespeare no se produce de manera aislada, sino que esta es percibida como parte del conjunto de actividades incluidas en el programa. Por lo tanto, el contacto con otros montajes, sean o no de obras de Shakespeare, de la misma o diferentes ediciones, influye en su recepción, dando lugar a las nociones aquí esgrimidas de memoria del festival y memoria de Shakespeare en el festival.

Otros festivales y, por supuesto, montajes que van más allá de la dramaturgia shakespeariana, pueden ser objeto de un análisis similar al aquí planteado. Los festivales de teatro, como indica el ejemplo del Festival de Aviñón y la representación en él de las obras de Shakespeare, tienen el potencial de activar mecanismos de recepción que son inherentes a este contexto, lo que hace de ellos contextos de recepción eminentemente distintos de otros entornos teatrales. El análisis de los mecanismos de programación, la activación de la memoria del festival y su influencia en las producciones $\mathrm{y}$

${ }^{13}$ El crítico mencionaba también que, finalmente, el castillo de Claudio aparecía "planqué sous la tour Eiffel" (Libiot, 2011: s. p.). 
coproducciones realizado en el presente artículo pone de relieve la importancia de examinar el contexto de representación y recepción en la creación de significado de los espectáculos teatrales. El estudio minucioso del significado conectado al contexto, por lo tanto, deja al descubierto una serie de particularidades de la recepción propias de los festivales de teatro que develan las especiales características de estos metaacontecimientos.

\section{REFERENCIAS BIBLIOGRÁFICAS}

ANÓNIMO (1947). “La Tragédie du Roi Richard II de William Shakespeare”. L'Accent, 7 de septiembre, s. p. Archivo del Festival de Aviñón, Maison Jean Vilar, Aviñón. (1953). "Vilar's Richard II. Striking Production by French Company". Scotsman, 10 de septiembre, s. p. Scotsman, Microfilm Collection, National Library of Scotland, Edimburgo.

Archambault, H. et Baudriller, V. (2008). "Éditorial”. En Programme 2008, Festival de Aviñón (ed.), 2. Aviñón: Festival de Aviñón.

Bely, P. (2008). "Au Festival d'Avignon, Thomas Ostermeier - Hamlet: La terre... enfin!" Tardone, 17 de julio. Disponible en línea: http://festivals.overblog.com/article-21301733.html [13/01/2021].

Bennet, S. \& CARSON, C., EDS. (2013). Shakespeare Beyond English. Cambridge: Cambridge University Press.

Bennet, S. (1990). Theatre Audiences: A Theory of Production and Reception. London / New York: Routledge.

CArlson, M. (1989). Places of Performance: The Semiotics of Theatre Architecture. Ithaca / London: Cornell University Press.

(2001). The Haunted Stage: The Theatre as Memory Machine. Ann Arbor: University of Michigan Press.

DARge, F. (2007). "L'Illusion magique du Roi Lear". Le Monde, 24 de julio, s. p. Archivo del Festival de Aviñón, Maison Jean Vilar, Aviñón.

Dornes, G. (1947). "Richard II de Shakespeare joué en Avignon”. Le Populaire, 6 de septiembre, s. p. Archivo del Festival de Aviñón, Maison Jean Vilar, Aviñón.

Edmondson, P.; Prescott, P. \& Sullivan, E., EDS. (2013). A Year of Shakespeare: Reliving the World Shakespeare Festival. London: Bloomsbury Arden Shakespeare.

Elfman, R. (2015). "Expert Spectatorship and Intra-Audience Relationships at the Globe to Globe 2012". En Shakespeare on the Global Stage, P. Prescott \& E. Sullivan (eds.), 163-190. London: Bloomsbury.

FALCON, C. (2007). “'L’illusion et les tentations de la création': Jean Vilar et La Tragédie du roi Richard II du premier festival d'Avignon au TNP”. En Shakespeare au XXe siècle. Mise(s) en scène, mise(s) en perspective de King Richard II, P. Drouet (ed.), 19-37. Rennes: Presses Universitaires de Rennes. 
Guerrero, I. (2017a). "A Festival Blockbuster: Romeo and Juliet at the Edinburgh Fringe and the Avignon Off". En Romeo and Juliet in European Culture, J. F. Cerdá, D. Delabastita \& K. Gregor (eds.), 247-262. Amsterdam / Philadelphia: John Benjamins Publishing Company.

(2017b). "Shakespeare in La Mancha: Performing Shakespeare at the Almagro Corral". SEDERI: Yearbook of the Spanish and Portuguese Society for English Renaissance Studies 27, 27-46. Disponible en línea: http://www.sederi.org/wpcontent/uploads/2017/12/27_02_Guerrero.pdf [02/01/2021].

(2020). "My native English now I must forgo': Global Shakespeare at the Edinburgh International Festival". Cahiers Élisabéthains: A Journal of English Renaissance Studies 130, 57-74. Disponible en línea: https://journals.sagepub.com/doi/full/10.1177/0184767820935129 [02/01/2021].

H., G. (1953). "Richard II 'À La Mode”'. The Evening Dispatch, 9 de septiembre, s. p. Archivo del Festival Internacional de Edimburgo, National Library of Scotland, Edimburgo.

HAN, J. (2008). "Une vision politique d'Avignon". L'Humanité, Supplement Septembre 2008, septiembre, s. p. Archivo del Festival de Aviñón, Maison Jean Vilar, Aviñón.

Hauptfleisch, T. ET AL., EDS. (2007). Festivalising!: Theatrical Events, Politics and Culture. Amsterdam: Rodopi.

HÉLIOT, A. (2015). “Avignon: Richard III fait oublier la dérouillée d'Oliver Py”. Le

Figaro, 7 de julio. Disponible en línea:

http://www.lefigaro.fr/theatre/2015/07/07/03003-20150707ARTFIG00187-

avignon-richard-iii-fait-oublier-la-derouillee-d-olivier-py.php [13/01/2021].

Huang, A. (2009). Chinese Shakespeares: Two Centuries of Cultural Exchange. Columbia: Columbia University Press.

Kennedy, D., ED. (1993). Foreign Shakespeare: Contemporary Performance. Cambridge: Cambridge University Press.

(2009). The Spectator and the Spectacle: Audiences in Modernity and Postmodernity. Cambridge / New York: Cambridge University Press.

Le Breton, B. (2008). "Un Hamlet qui décoiffe au Festival d'Avignon”. Ouest France, 18 de julio, s. p. Archivo del Festival de Aviñón, Maison Jean Vilar, Aviñón.

LiBiot, E. (2011). "Hamlet sur des œufs". L'Express, 2-8 de noviembre, s. p. Archivo del Festival de Aviñón, Maison Jean Vilar, Aviñón.

Maldonado, A. (2008). "Hamlet - Ressenti de Alain Maldonado". En Ressentis du Groupe Miroir - Festival d'Avignon 2008 2, 96. Archivo del Festival de Aviñón, Maison Jean Vilar, Aviñón.

(2015). “Traversée 2015 d'Alain”. En Ressentis du Groupe Miroir - Festival d'Avignon 2015 9, 330-334. Archivo del Festival de Aviñón, Maison Jean Vilar, Aviñón. 
MARCH, F. (2010). "Richard II in the Honour Court of the Papal Palace: Forgetting Shakespeare in order to find him?" Les Cahiers de La Licorne, Les Cahiers Shakespeare en devenir - The Journal of Shakespearean Afterlives. "L'Eil du spectateur 2010-11". Disponible en línea: http://shakespeare.edel.univpoitiers.fr/index.php?id=469 [13/01/2021].

(2012a). "Amateur reviewing at the Avignon Festival: The Mirror Group". "Nothing if not critical": International Perspectives on Shakespearean Theatre Reviewing, Cahiers Élisabéthains. A Journal of English Renaissance Studies 81, 133-139.

(2012b). Shakespeare au Festival d'Avignon: configurations textuelles et scèniques, 2004-2011. Montpellier: L’Entretemps Éditions.

(2014). "Shakespeare at the Avignon Festival: Breaking Down the Walls". Litteraria Pragensia. Studies in Literature and Culture 24, 72-83.

(2018). "Translating Shakespeare into Postwar French Culture: The Origins of the Avignon Festival (1947)". Shakespeare Studies 46, 59-69.

MARCH, F. \& VAlls-Russell, J. (2016). "Shaking up Shakespeare in Europe - Two New Festivals”. Cahiers Élisabéthains: A Journal of English Renaissance Studies 90, 155-170.

MASsAi, S., ED. (2005). World-wide Shakespeares: Local Appropriations in Film and Performance. London: Routeledge.

McConachie, B. (2010). "International Festivals." En Theatre Histories: An Introduction, G. J. Williams (ed.), 485-488. London / New York: Routledge.

Menard, A. (2011). "Macaigne met en scène le cadavre de la société du spectacle". Théâtre Contemporain, 9 de julio, s. p. Archivo del Festival de Aviñón, Maison Jean Vilar, Aviñón.

Morse, R. (2008). "Monsieur Macbeth: from Jarry to Ionesco", Shakespeare Survey 57, 112-125.

Mouret, V. (2007). "Les Ressentis concernant le Roi Lear". Ressentis du Groupe Miroir - Festival d'Avignon 2007 1, 149. Archivo del Festival de Aviñón, Maison Jean Vilar, Aviñón.

PERni, R. (2015). "El Año de Ricardo and the Degeneration of Europe". The Grove. Working Papers on English Studies 22, 135-147. Disponible en línea: http://revistaselectronicas.ujaen.es/index.php/grove/article/view/2702 [13/01/2021].

Prescott, P. \& Sullivan, E., EDS. (2015). Shakespeare on the Global Stage. London: Bloomsbury.

PurCell, S. (2015). "Shakespeare Spectatorship". En Shakespeare on the Global Stage, P. Prescott y E. Sullivan (eds.), 133-162. London: Bloomsbury.

Py, O. (2015). “Je suis l'autre”. En Programme 2015, Festival de Aviñón (ed.), 1. Aviñón: Festival de Aviñón. 
Rioux, C. (2007). "Merdre Alors! Ubu et Macbeth: le pouvoir pile ou face". Le Devoir, 21 de julio, s. p. Archivo del Festival de Aviñón, Maison Jean Vilar, Aviñón.

Savacool, J. K. (1948). "Letter to Mr Lewis Fuke, New York Times Drama Editor", 20 de julio, s. p. Archivo del Festival de Aviñón, Maison Jean Vilar, Aviñón.

Schoenmakers, H. (2007). "Festivals, Theatrical Events and Communicative Interactions". En Festivalising!: Theatrical Events, Politics and Culture, T. Hauptfleisch et al. (eds.), 39-47. Amsterdam: Rodopi.

SchwartZ-Gastine, I. (2007). "Richard II revu et corrigé par Ariane Mnouchkine: retour sur une transposition”. En Shakespeare au XXe siècle. Mise(s) en scène, mise(s) en perspective de King Richard II, P. Drouet (ed.), 55-67. Rennes: Presses Universitaires de Rennes.

Solis, R. (2001). "Partie d'affects chez Hamlet". Libération, 20 de julio, s. p. Archivo del Festival de Aviñón, Maison Jean Vilar, Aviñón.

Worthen, W. B. (2003). Shakespeare and the Force of Modern Performance. Cambridge: Cambridge University Press.

Zaiontz, K. (2018). Theatre and Festivals. London: Palgrave.

Worthen, W. B. (2003). Shakespeare and the Force of Modern Performance. Cambridge: Cambridge University Press.

Fecha de recepción: 20/01/2021

Fecha de aceptación: 24/02/2021 